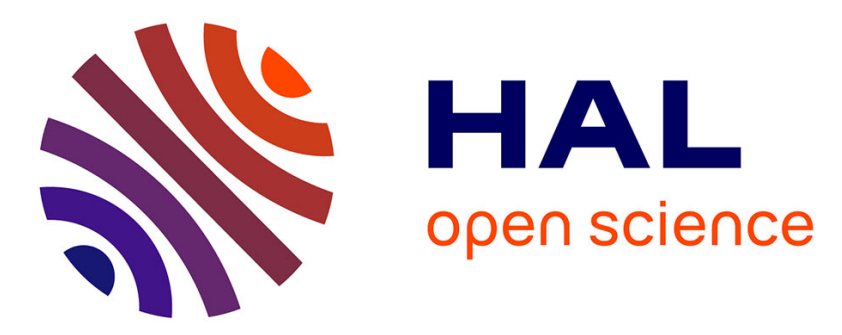

\title{
Analysis of wedge splitting test on refractory castable via integrated DIC
}

Rafael Vargas, Jan Neggers, Rodrigo B Canto, J A Rodrigues, François Hild

\section{To cite this version:}

Rafael Vargas, Jan Neggers, Rodrigo B Canto, J A Rodrigues, François Hild. Analysis of wedge splitting test on refractory castable via integrated DIC. Journal of the European Ceramic Society, 2016, 36, pp.4309 - 4317. 10.1016/j.jeurceramsoc.2016.07.007 . hal-01383919

\section{HAL Id: hal-01383919 https://hal.science/hal-01383919}

Submitted on 19 Oct 2016

HAL is a multi-disciplinary open access archive for the deposit and dissemination of scientific research documents, whether they are published or not. The documents may come from teaching and research institutions in France or abroad, or from public or private research centers.
L'archive ouverte pluridisciplinaire HAL, est destinée au dépôt et à la diffusion de documents scientifiques de niveau recherche, publiés ou non, émanant des établissements d'enseignement et de recherche français ou étrangers, des laboratoires publics ou privés. 


\title{
Analysis of Wedge Splitting Test on Refractory Castable via Integrated DIC
}

\author{
R. $\operatorname{Vargas}^{\mathrm{a}}$, J. Neggers ${ }^{\mathrm{b}}$, R.B. Canto ${ }^{\mathrm{a}}$, J.A. Rodrigues ${ }^{\mathrm{a}}$, F. Hild ${ }^{\mathrm{b}, *}$ \\ ${ }^{a}$ Federal University of São Carlos (UFSCar), Department of Materials \\ Engineering (DEMa) \\ Rodovia Washington Luis, km 235, 13565-905 - São Carlos-SP Brazil \\ ${ }^{b}$ LMT, ENS Cachan / CNRS / Université Paris-Saclay \\ 61 avenue du Président Wilson, 94235 Cachan, France
}

\begin{abstract}
One of the key mechanical properties of refractories is their toughness. The latter can be evaluated via wedge splitting tests. One such test is analyzed herein with an integrated approach to digital image correlation. The position of the crack tip, stress intensity factors and T-stress are estimated on two faces of the tested sample made of a refractory castable during the whole cyclic test. It is shown that the change of energy release rate with the crack length can be determined at each time step of the experiment.
\end{abstract}

Keywords: Castables; Crack growth resistance; Photomechanics; R-curve

\section{Introduction}

Refractory castables are known for their capability to maintain enough mechanical and chemical properties in extreme environments [1]. They are

\footnotetext{
*Corresponding author

Email address: hild@lmt.ens-cachan.fr (F. Hild)
} 
used as insulators in industries that produce base materials such as metals, ceramics and petrochemicals, where high temperatures and/or corrosive processes are involved (e.g., melting metals or cracking petrol). The proper material selection for each application not only improves the security but also increases the lifetime [2]. The brittle fracture of these materials leads to the need for a good understanding of the mechanical behavior (e.g., to prevent accidents). Minimizing thermal shock damage by tailoring the microstructure with respect to crack propagation may increase their lifetime (and reduce its uncertainty), thereby reducing costs and improving the safety of the applications. Investigating tests with stable crack propagation is useful to better understand the mechanisms of fracture and quantify the relevant mechanical parameters.

Stable crack propagation is achievable using, for instance, the Wedge Splitting Test (or WST $[3,4,5]$ ) in which the elastic energy stored in the machine is minimized. This test, which is very suitable for brittle materials, is very challenging because the displacement (and strain) levels remain very small. The purpose of this work is to assess whether a single WST is suited for the evaluation of R-curve behavior of such materials. Among the classical methods used for R-curve measurements, one possibility is using long cracks (i.e., longer than $1 \mathrm{~mm}$ ) with stable propagation in standard testing geometries of fracture mechanics [6]. The crack length is estimated as a function of the compliance obtained on the load-displacement curve after comparing with theoretical values [7]. If a cyclic experiment is chosen, there are discus- 
sions on how to calculate the compliance as the reference is not obvious in the case of hysteresis in the loading/unloading cycles [6]. The crack length can also be estimated by direct observation [8] but it may be different for each operator.

An approach that was successfully used to monitor cracks is Digital Image Correlation (DIC) $[9,10,11]$. Full displacement fields are measured instead of few point data (e.g., extensometry, load). This technique does not directly depend on the operator and it can follow crack propagation, namely, different crack positions can be determined in the same test as it propagates [12]. To determine Stress Intensity Factors (SIF) and crack tip positions, the measured displacement fields are subsequently post-processed via projections onto known solutions of fractured elastic media. In the case of brittle material fracture it is assumed that, apart from the vicinity of the crack tip, the material behaves elastically. In this specific case, Williams' series [13] describe the stress and displacement fields as functions of mechanical parameters for different fracture modes. A least-squares fit using Williams' series enables the SIF to be evaluated $[9,10,11]$ provided the crack tip position is known [14]. Dehnavi et al. [15] showed that this method may provide more accurate results compared to photoelasticity when evaluating SIFs.

Another method for estimating SIFs and energy release rates using measured displacements fields consists of performing numerical simulations via, say, Finite Element (FE) analyses. Once the crack tip position is known, it is possible to evaluate the SIFs and T-stresses via standard FE extracting 
techniques [16]. This analysis has been applied to WST on PMMA. DIC has also been utilized to characterize micro- and macrocracking in magnesia and magnesia spinel materials $[17,18]$. The aim of the present study is to determine the whole history of fracture mechanics parameters of a refractory castable.

In this paper, an Integrated Digital Image Correlation (I-DIC [14]) approach is followed for evaluating the amplitudes of the fields in Williams' series to analyze the reported WST. Instead of first measuring the displacements and then projecting them onto William' series, the two steps are integrated into a single one where the sought amplitudes are a direct result of the registration method. This approach bypasses the need for post-processing the displacement data, thereby reducing errors in the re-projection process [12]. This is of particular importance in the present case since the displacements are very small. The paper is organized as follows. First the experimental configuration and the studied material are introduced. The integrated DIC framework is then summarized in order to follow crack propagation, and estimate stress intensity factors and T-stress histories. The procedure is then applied to the pictures of two faces of the sample acquired during the test. It is shown that the R-curve behavior of the studied material can be obtained from the analysis of a single test. 


\section{Wedge Splitting Test}

The geometry of the WST specimen used in this work is shown in Figure 1(a). A right cuboid $100 \mathrm{~mm}$ in height, $72.5 \mathrm{~mm}$ in thickness, and $100 \mathrm{~mm}$ in width is chosen. The loading was applied by the wedge to the cylinders to open the specimen in pure mode I presumably. The test was driven with a controlled velocity of the machine actuator set to $1.3 \mu \mathrm{m} / \mathrm{s}$. The sample contains two vertical grooves (i.e., a local thickness reduction of $7 \mathrm{~mm}$ ) in the middle of front and back faces to guide crack propagation along a straight line, and the specimen was only supported at the bottom on a line passing through both grooves. The test consisted of five cycles (see Figure 1(b)) with the last unloading starting at $70 \%$ of the maximum applied load to ensure that the main crack has not entirely propagated through the sample. The pre-load was set to $30 \mathrm{~N}$, which was the value used to define the unloaded state between cycles.

Figure 1 about here

This test was performed on a class $\mathrm{C}$, anti-erosive commercial refractory, with ultra-low cement content (i.e., $0.2 \mathrm{wt} \%<\mathrm{CaO}<1.0 \mathrm{wt} \%$ ), and $45 \mathrm{wt} \%$ $\mathrm{Al}_{2} \mathrm{O}_{3}, 1.2$ wt $\% \mathrm{Fe}_{2} \mathrm{O}_{3}, 50$ wt $\%$ of $\mathrm{SiO}_{2}$ for its chemical composition. The typical mineralogical composition of the material consists of quartz $\left(\mathrm{SiO}_{2}\right)$, mullite $\left(\mathrm{Al}_{6} \mathrm{Si}_{2} \mathrm{O}_{1} 3\right)$, kyanite $\left(\mathrm{Al}_{2} \mathrm{SiO}_{5}\right), \beta$-cristoballite $\left(\mathrm{SiO}_{2}\right)$ and alumina $\left(\mathrm{Al}_{2} \mathrm{O}_{3}\right)$ [19]. With a firing temperature close to $540{ }^{\circ} \mathrm{C}$, there is no phase transformation from $\alpha$-quartz to $\beta$-quartz, which would lead to expansion. 
However, the anisotropic phases could induce different thermal strains, which can initiate and propagate cracks in the specimen [20]. These microcracks along with some weakly bonded grains to the matrix may debond and cause an R-curve behavior. For the mechanical properties of the studied material, the Young's modulus is equal to $17 \mathrm{GPa}$ and the Poisson's ratio to 0.2. Further characterization of the material analyzed herein can be found in Refs. [19, 21].

The images of the two lateral surfaces were taken using two cameras (Canon T5 model) with 28-135 mm lenses and the illumination was provided by LED lamps. For each face, 313 pictures were acquired with a rate of one frame every $8 \mathrm{~s}$. The cameras were triggered by the testing machine controller. The definition of the pictures is $2100 \times 1653$ pixels and their dynamic range is of the order of 58,000 gray levels. The physical size of one pixel was $62 \mu \mathrm{m}$. To illustrate the challenges faced with such an experiment, Figure 2 shows the measured displacement field in both directions via T3-DIC (see Section 3.1) for the maximum load when the rigid body translations have been removed. The maximum amplitude is very small (i.e., 0.5 pixel or $31 \mu \mathrm{m}$ at the most). This type of test and material is therefore very challenging for DIC analyses since the signal to noise ratio is extremely small [12].

Figure 2 about here 


\section{Parameter Extraction Procedure}

\subsection{Digital Image Correlation}

Digital Image Correlation (DIC) consists of using images to measure the motion of material points due to, say, mechanical loadings [22]. These images can be $2 \mathrm{D}$ or $3 \mathrm{D}$ pictures and the scale of the displacements mainly depends on the imaging device that leads to physical sizes of pixels (or voxels) ranging from nanometers to kilometers [23]. Its increasing popularity is partly explained by the constant improvements of DIC schemes and new imaging devices (e.g., digital cameras with always increasing definitions) along with the possibilities of getting full-field measurements instead of local point data.

Let us consider a simple $2 \mathrm{D}$ case where $f$ is the image of the reference configuration and $g$ a picture of the deformed sample. In the absence of noise, gray level conservation reads

$$
f(\mathbf{x})=g(\mathbf{x}+\mathbf{u}(\mathbf{x}))
$$

As there is always some noise during acquisition, the sum of squared differences is minimized over the region of interest (ROI)

$$
\phi=\sum_{R O I}(f(\mathbf{x})-g(\mathbf{x}+\mathbf{u}(\mathbf{x})))^{2}
$$

with respect to a chosen parameterization of the displacement field. This approach is optimal for white, homogeneous and Gaussian noise [23]. The displacement field is parameterized with a finite number of fields $\boldsymbol{\Psi}_{i}$ with 
unknown amplitudes $v_{i}$

$$
\mathbf{u}(\mathbf{x})=\sum_{i} v_{i} \boldsymbol{\Psi}_{i}(\mathbf{x})
$$

so that $\mathbf{u}$ depends on the vector $\{\boldsymbol{v}\}$ gathering all amplitudes $v_{i}$. Without prior knowledge on the kinematics the best approach would be choosing a robust $\boldsymbol{\Psi}_{i}$ that works in the majority of cases, such as a finite elements discretization [24]. In the following, T3-DIC will be used. It is based on a finite element discretization made of 3-noded linear elements [25, 26]. The degrees of freedom in such a discretization have a local support, which is slightly bigger than an element due to the connectivity of the mesh. However, this local support makes the solution susceptible to acquisition noise [26, 27]. This is of particular importance for the case at hand for which the displacements have variations in displacement of the order of tens of micrometers at the most.

A direct improvement for an FE-based discretization is to disconnect nodes along the crack on the mesh using the crack path, which is obtained from the DIC residuals for instance $[26,28]$ or by resorting to enriched (i.e., X-FEM) of kinematics [29]. However, a more integrated path is to reduce the allowable kinematics to exactly those described by closed-form solutions of the experiment [14] in which $v_{i}$ are directly the sought mechanical parameters instead of nodal displacements. In cracked elastic media, Williams' series provide closed-form expressions for the fields $\boldsymbol{\Psi}_{i}$ under plane stress and plain strain states $[13,30]$. If the latter ones are directly used in an integrated DIC code $[14,12]$, then no post-processing is needed to evaluate 
the fracture mechanics parameters (e.g., crack tip position, SIF, T-stress).

In the integrated DIC code, the fields $\boldsymbol{\Psi}_{i}$ introduced in Equation (3) correspond to those found in Williams' series [13]. Considering the origin at the crack tip with the crack face on the negative $x$-axis, the displacements fields are written as [12]

$$
\mathbf{u}(\mathbf{z})=\sum_{j=I}^{I I} \sum_{n=p_{i}}^{p_{f}} \omega_{n}^{j} \boldsymbol{\psi}_{n}^{j}(\mathbf{z}),
$$

where the vector fields are defined in the complex plane

$$
\mathbf{z}=x+y i=r \exp (i \theta)
$$

and $j=I$ is related to mode I (opening) regime, and $j=I I$ to mode II (shearing). The corresponding fields are described by

$\boldsymbol{\psi}_{n}^{I}=\frac{A(n)}{2 \mu \sqrt{2 \pi}} r^{n / 2}\left[\kappa \exp \left(\frac{i n \theta}{2}\right)-\frac{n}{2} \exp \left(\frac{i(4-n) \theta}{2}\right)+\left((-1)^{n}+\frac{n}{2}\right) \exp \left(-\frac{i n \theta}{2}\right)\right]$

and

$\boldsymbol{\psi}_{n}^{I I}=\frac{i A(n)}{2 \mu \sqrt{2 \pi}} r^{n / 2}\left[\kappa \exp \left(\frac{i n \theta}{2}\right)+\frac{n}{2} \exp \left(\frac{i(4-n) \theta}{2}\right)+\left((-1)^{n}-\frac{n}{2}\right) \exp \left(-\frac{i n \theta}{2}\right)\right]$

where $\kappa$ is equal to $(3-\nu) /(1+\nu)$ for plane stress states or $3-4 \nu$ for plane strain states, $\nu$ the Poisson's ratio, $r$ the distance from the crack tip, $\theta$ the angular position, and $A(n)$ are defined by

$$
A(n)=\cos \left(\frac{n \pi}{2}\right)^{2}+\sin \left(\frac{n \pi}{2}\right)
$$


Equations (6) and (7) provide the sensitivity fields that after being multiplied by the amplitudes $\omega_{n}^{j}$ provide the total displacement fields. Equation (8) inputs consistent vector directions (for mode I and mode II) at the crack vicinity for the fields related to odd values of $n$ and is valued as 1 or -1 for integer values of $n$. Amplitudes $\omega_{1}^{I}$ and $\omega_{1}^{I I}$ give access to SIFs for mode I $\left(K_{I}\right)$ and mode II $\left(K_{I I}\right)$, respectively. The amplitude $\omega_{2}^{I}$ provides the socalled T-stress, $\omega_{2}^{I I}$ the rigid body rotation; the use of two additional terms in the series, $\omega_{0}^{I}$ and $\omega_{0}^{I I}$, allow for rigid body translation corrections. Although not usual, negative values of $p_{i}$ can be used to account for nonlinear effects in the vicinity of the crack tip $[31,30,12]$. These negative $n$ fields are referred to as the super-singular fields.

Considering a straight crack propagation along the $x$-axis, the displacement related to a mispositioned crack by a small distance $d$ reads [31]

$$
\mathbf{u}(\mathbf{z}+d)=\mathbf{u}(\mathbf{z})+d \frac{\partial \mathbf{u}(\mathbf{z})}{\partial \mathbf{z}}
$$

and it is noted that

$$
-\frac{\partial \boldsymbol{\psi}_{n}^{j}}{\partial \mathbf{z}}=\frac{n}{2} \boldsymbol{\psi}_{n-2}^{j}
$$

Equation (4) can be substituted in Equation (9), in addition to the property shown in Equation (10) to obtain

$$
\tilde{w}_{n}^{j}=w_{n}^{j}-d \frac{(n+2) w_{n+2}^{j}}{2}
$$

where $\tilde{w}_{n}^{j}$ is the amplitude of the series after the shift and $w_{n}^{j}$ before it. 
Because of the singular character for $n=-1$ when $r=0, \tilde{w}_{-1}^{I}$ cancels out

$$
d=\frac{2 w_{-1}^{I}}{w_{1}^{I}},
$$

which provides an estimation of crack tip shift to find the correct position.

\subsection{Methodology}

The proposed methodology consists of different steps:

1. The crack path is assumed to be straight (since there is a groove on two opposite faces to guide crack propagation, see Figure 1(a));

2. The initial guess of the crack tip position is based, at first, upon the transverse strain field along the groove [32], which is determined from the displacement measured with T3-DIC (e.g., see Figure 2);

3. The Williams Series parameters are chosen e.g., radial normalization (see section 3.2.1), and a truncation proposal to evaluate the infinite series, which is discussed in Section 3.2.2;

4. Integrated-DIC is performed to find the amplitudes for the Williams series fields using a fixed crack-tip position;

5. The crack-tip position is updated using the estimated crack shift $d$ as described in Equation (12);

6. Steps 4 and 5 are repeated until convergence.

\subsubsection{Normalization}

The farther from the crack tip the displacements are assessed, the more terms of Williams' series are needed [33, 34]. The higher order terms combined with large distances lead to floating point rounding errors due to the 
wide range of values present in the $\psi_{n}^{j}$ fields. For that reason, a normalization on the radius is introduced

$$
r^{*}=\frac{r}{r_{0}},
$$

where $r_{0}$ is the chosen normalization parameter. The chosen normalization improves floating point accuracy for high order terms without any impact on the solution space by reducing the range of $r^{*}$, and thus removing conditioning issues related to rounding errors. In the present work $r_{0}$ and the evaluation radius are chosen such that $r^{*} \in[0,1]$.

The displacement field is rewritten as

$$
\mathbf{u}(\mathbf{z})=\sum_{j=I}^{I I} \sum_{n=p_{i}}^{p_{f}} b_{n}^{j} \widetilde{\boldsymbol{\psi}}_{n}^{j}(\mathbf{z}), \quad \text { with } \widetilde{\boldsymbol{\psi}_{n}^{j}}(\mathbf{z})=\frac{\boldsymbol{\psi}_{n}^{j}(\mathbf{z})}{r_{0}^{n / 2}}
$$

so that the corresponding amplitudes become

$$
b_{n}^{j}=\omega_{n}^{j} r_{0}^{n / 2}
$$

\subsubsection{Number of Terms of the Series}

As seen in Equation (4) it is necessary to choose $p_{i}$ and $p_{f}$ to truncate the series so it can be numerically solved. Even though super-singular fields are not mandatory, the proposed approach needs $p_{i}=-1$ for the estimation of the crack tip position (Equation (12)). As proposed in earlier studies, the value $p_{i}=-3$ is considered to account for non-linear kinematics surrounding the crack tip [30, 12]. Besides the -3 term, the domain applied for IntegratedDIC is shaped to exclude the direct vicinity of the crack, thereby reducing 
the impact of nonlinear effects on the results (Figure 5). Henninger et al. [30] have shown that $p_{f}=7$ was sufficient to describe the analysis of a CT test for an elastoplastic material in small scale yielding regime. In the case of the WST, the studied material is brittle (or quasi-brittle) and a bigger radius of

evaluation was applied to use more information from the images. Because of these differences, analyses will be run to validate the choice of $p_{f}$ and the normalization procedure.

\section{Results and Discussions}

This section shows the results on the WST (Figure 1(a)) using the methodology described in Section 3. The integrated DIC routine is part of the Correli 3.0 framework, which is developed at LMT-Cachan [35].

\subsection{Front Face}

The analysis of all 312 image pairs is performed with different numbers of terms of Williams' series. In Figure 3 the results are shown for three different truncations (i.e., $\left.p_{f}=[3,8,13]\right)$.

\section{Figure 3 about here}

The following observations are drawn:

- The I-DIC method to find a proper crack tip converges from the third cycle on for $p_{f}=3$. The other truncations (i.e., $p_{f}=8$ and $p_{f}=13$ ) find the crack tip position from the start even though extremely small 
displacements occur at the beginning of the test (i.e., very low signal to noise ratio);

- $p_{f}=3$ underestimates $K_{I}$ and overestimates the crack length after the third cycle peak when compared to the other truncations even though it follows the same trend. It is worth noting that the crack length vanishes at the root of the pre-notch;

- The truncations $p_{f}=8$ and $p_{f}=13$ provide identical results meaning that $p_{f}=8$ gives an equivalent description of the kinematics when compared with series with a higher number of terms (for the three studied truncations);

- All three analyzed truncations show that the studied WST is close to pure mode I as the levels of $K_{I I}$ are approximately equal to zero;

- The T-stress value increases upon loading and decreases in the unloading phase as expected. The T-stress related to $p_{f}=3$ deviates with the cycles from the levels observed when $p_{f}=8$ and $p_{f}=13$. In the last cases, a convergence to same values is noted and a maximum level around $4 \mathrm{MPa}^{2}$ is reached from the third to the fifth cycle.

The gray level residual allows the user to evaluate which truncation variant describes the kinematics of the tests better. For comparison purposes

\footnotetext{
${ }^{2}$ It is worth noting that with the chosen field $\boldsymbol{\psi}_{2}^{I}$, a positive T-stress is compressive.
} 
T3-DIC is also run and considered as a reference since more degrees of freedom (i.e., nodal displacements) are measured in comparison with I-DIC. Consequently T3-DIC can better describe the overall kinematics and would have lower residuals but may become more sensitive to acquisition noise. For this comparison, the residuals for any DIC analysis read

$$
R(\mathbf{x})=f(\mathbf{x})-g\left(\mathbf{x}+\mathbf{u}_{\text {meas }}(\mathbf{x})\right),
$$

which are the gray level differences between the reference image $f$ and the deformed image $g$ corrected by the measured displacement field $\mathbf{u}_{\text {meas }}$. For a given loading step, the root mean square (RMS) gray level is considered to globally evaluate the quality of registration

$$
\rho(\mathbf{x})=\operatorname{RMS}(R(\mathbf{x})) .
$$

When two DIC techniques are compared, the difference $\Delta \rho$ over the same Region Of Interest (ROI) is considered

$$
\Delta \rho=\rho_{\mathrm{I}-\mathrm{DIC}\left(p_{f}\right)}-\rho_{\mathrm{T} 3-\mathrm{DIC}} .
$$

The RMS residuals $\rho$ and $\Delta \rho$ normalized by the dynamic range (i.e., number of gray level values) are shown in Figure 4 for the three different truncations. Figure 4(a) shows $\rho$ over the whole ROI over which T3-DIC or I-DIC was performed. The global residuals are very close, thereby indicating that both image registrations have converged. It is worth noting however that the ROIs are not identical for the four analyses since the ROI for T3-DIC is 
rectangular and nearly covers the whole speckled surface (Figure 2), whereas I-DIC is based on circular ROI (Figure 5). This difference explains the fact that the residual of T3-DIC is slightly higher than those of the I-DIC because the T3 result contains the crack path, which inflates the residual (marginally in the present case).

The same trend, which is seen on every curve (apart from $p_{f}=3$ at the beginning), shows that the chosen kinematics (i.e., Williams' series) is consistent with the analyzed case. High values of $\rho$ for the first two cycles for $p_{f}=3$ are observable (i.e., the orange line is out of the range of Figure 4(a)). This result is due to the inaccurate crack tip position for the same truncation, corroborating the fact that a higher $p_{f}\left(i . e ., p_{f}=8\right)$ is more suitable for this analysis.

Figure 4 about here

All the reported gray level residuals show fluctuations from one analyzed picture to the next. These fluctuations are due to illumination variations during the test. It is believed that part of the variations observed in Figure 3 are a direct consequence of the unstable illumination and are not actually present in the experiment. The fact that the same fluctuations are observed on T3-DIC and I-DIC results substantiates that statement.

In Figure 4(b) the residual difference is now computed for the same ROIs in I-DIC and T3-DIC. A generally positive difference is obtained, which indicates that I-DIC residuals are slightly higher than those of T3-DIC analyses. 
This is to be expected because the number of degrees of freedom are significantly reduced in I-DIC in comparison with T3-DIC leading to a much more restricted solution space. The fact that the differences are insignificant is an additional validation that Williams' series form a suitable reduced kinematic basis. It is also interesting to see how much $p_{f}=3$ deviates from the other two truncations as the crack grows (see Figure 4(b) after image 70). This trend reinforces the fact that higher $p_{f}$ are required, especially for longer cracks.

In all the analyses performed herein, 2D-DIC procedures were carried out. One limitation is associated with out-of-plane motions [36, 37]. In the present case they are extremely small. Had they been more significant, the I-DIC residuals would not have remained so low and very close to T3-DIC levels since the reduced kinematic basis does not account for such effects.

The oscillations on the measured SIFs, crack length and T-stress are believed to be related to the very small amplitudes of measured displacements. Figure 2 already illustrated the challenges faced in the present case. Figure 5 shows the displacements in both directions for the same image without considering the rigid body motions, i.e., displacements related to the $n=0$ fields that account for rigid body translations and also $n=2$ (mode II only), namely rigid body rotation, have been removed. In this figure the fracture mechanics kinematics is related to subpixel displacements whose dynamic range is small (i.e., \pm 0.25 pixel at the most). Thanks to the applied I-DIC framework, it is possible to get trustworthy information related to fracture 
mechanics parameters during the whole test considering the low signal to noise ratio.

\section{Figure 5 about here}

In the present case $p_{f}=8$ is the best compromise overall, since adding more terms (e.g., $\left.p_{f}=13\right)$ does not change the results nor significantly decreases registration residuals. It is important to note that in the literature it is found that higher order terms could be important when describing the fields far from the crack tip, especially for bigger cracks [33, 34]. The residuals indicate that a moderate number of terms is sufficient provided the SIFs, Tstress and crack tip locations have converged.

\subsection{Back Face}

For the studied experiment, images of both faces were taken during loading. The same analysis is conducted on the back face and the results are shown in Figure 6. Not only are the overall trends identical, but all the observations made for the front face are also valid. The only notable exception is that results with the first truncation (i.e., $p_{f}=3$ ) are closer to the other ones.

Figure 6 about here

The comparison between I-DIC and T3-DIC residuals is shown in Fig-

ure 7 . For this face of the specimen the images were noisier (when compared to the front face) but it is still possible to see that I-DIC describes the actual 
kinematics well since very similar residuals are achieved when compared with the freer T3-DIC result. The same trend is seen for $p_{f}=3$, which deviates from the other truncations. Further, in the present case $\Delta \rho$ is always positive, i.e., T3-DIC better describes the kinematics. However, the differences remain very small, again validating the choice of the kinematic basis. The best truncation corresponds to $p_{f}=8$ as for the front face.

Figure 7 about here

\subsubsection{Coupled Analysis}

For comparison purposes, the results for $p_{f}=8$ obtained for both faces are shown in Figure 8. Interestingly, crack propagation is not strictly identical on both sides. In the case of a WST on brittle materials, it is unlikely to maintain a perfect alignment of the wedge as the crack propagates. $K_{I}$ increases as the crack propagates, which is an indication of the R-curve behavior. One kink in the reported $K_{I}$ SIF is visible at the third cycle. It is directly related to the difference in crack length from the two sides. At that moment, the crack propagates faster on the back, thereby weakening the stresses causing the measured $K_{I}$ on this side to be lower. On both sides, $K_{I I}$ remains close to zero. The fluctuations on $K_{I I}$ are believed to be related to noise. Consequently, it can be concluded that the test is in quasi pure mode I condition. At the very end, it appears that $K_{I I}$ starts to increase slightly, but a maximum absolute value of $0.1 \mathrm{MPa} \sqrt{\mathrm{m}}$ is negligible compared to the maximum $K_{I}$ level of $2 \mathrm{MPa} \sqrt{\mathrm{m}}$. 
Figure 8 about here

The T-stress corresponds to the stress parallel to the crack propagation direction [38]. The absolute increase of T-stress with loading is consistent with rising SIFs. Conversely, it decreases in amplitude when $K_{I}$ decreases. The fluctuations of the T-stress are at the most equal to $\pm 0.5 \mathrm{MPa}$, which correspond to strain fluctuations of the order of $\pm 3 \times 10^{-5}$. These strain fluctuations are extremely small. They are related to measurement uncertainties. Further, as the studied material is less brittle than most refractories, thus easier to achieve stable crack propagation, the test was performed with faster loading rate than usual. Figure 1(b) shows the loading curve of the cyclic test with the five cycles. Small oscillations are observed, which in turn explain part of the fluctuations on the reported SIFs and T-stress histories.

It is worth noting that there is a $20 \%$ difference between the crack tip positions, stress intensity factors and T-stress levels between the two faces. Had only one camera been used, it would have led to a $\pm 10 \%$-difference with respect to their averages. This point underlines the fact that two cameras are highly advised to be used for WST experiments.

Let us consider the dimensionless crack length

$$
\alpha=\frac{a}{H_{\text {eff }}}
$$

Plotting the average energy release rate $\mathcal{G}$ measured from the analyses of both faces as a function of the average values of $\alpha$ enables the R-curve behavior to be investigated (Figure 9). In the present case, only the loading part of each 
cycle is reported. The rising trend of the curve means that more energy is needed for each increment of crack propagation. It is interesting to note that a steeper slope is observed when $\alpha>0.7$. This result is compatible with the equations used for R-curve calculations [7], although none of these equations were assumed herein. The mean energy release rate when $0.3<\alpha<0.7$ is approximately equal to $35 \mathrm{~J} / \mathrm{m}^{2}$. For the the whole propagation curve, the average value is $60 \mathrm{~J} / \mathrm{m}^{2}$.

Figure 9 about here

\section{Conclusions and Perspectives}

Integrated DIC was successfully used to analyze a wedge splitting test on a refractory castable. A fully automated procedure was implemented to analyze a series of more than 300 pictures. By analyzing the correlation residuals, it enabled the choice of a reduced kinematic basis based upon Williams' series expansion to be validated. This first step is crucial to make sure that the reported results are trustworthy even though the experimental configuration is very challenging for non-integrated DIC purposes.

One key aspect related to cracked media is the location of the crack tip. In the present case, because a speckle pattern was applied to the surfaces and the presence of the grooves, visual estimates were not possible. The use of the first super-singular field proved to be reliable. Consequently, it was shown that it is possible to measure crack lengths, $K_{I}, K_{I I}$ and $T$-stresses even though the displacement amplitude remains very small. The measurements 
on both faces of the specimen are important as crack propagation may not be aligned with the out-of-plane direction. Measurements on a single side on the WST could lead to biased results, even though it is possible that both faces follow the same trend as seen in the test reported herein.

With the knowledge of $K_{I}, K_{I I}$ and crack length, the R-curve behavior is accessible. For the studied material the R-curve behavior is clearly revealed by using a single experiment. This result proves the feasibility of the integrated DIC framework for the quantification of cracking in refractories via global parameters such as stress intensity factors, and T-stresses. To further validate the present framework the next step may be to compare such results with standard procedures (e.g., via work of fracture estimates [39]). A study to check if lower order terms of Williams' series are related to the Fracture Process Zone [31, 30, 12] or other fracture mechanisms could be evaluated with a known microstructure and material behavior by focusing more about the crack tip. Last the estimation of R-curve behavior with the proposed method on other materials and compositions may also be undertaken.

\section{Acknowledgements}

This work was partially supported by BPI France (DICCIT project). JAR thanks CNPQ for the productivity scholarship, grant \#307127/2013-3. RV's stay at LMT was supported through an RIA scholarship, grant \#2015/111047, São Paulo Research Foundation (FAPESP). 


\section{References}

1. Lee, W.E., Vieira, W., Zhang, S., Ghanbari Ahari, K., Sarpoolaky, H., C., P.. Castable refractory concretes. International Materials Reviews 2001;46(3):145-167.

2. Wachtman, J.. Materials and Equipment - Whitewares - Refractory Ceramics - Basic Science: Ceramic Engineering and Science Proceedings, Volume 16. No. 1 in Ceramic Engineering and Science Proceedings. Wiley; 2009.

3. Tschegg, E.. Equipment and appropriate specimen shapes for tests to measure fracture values. Patent AT-390328; Austrian Patent Office; 1986.

4. Brühwiler, E., Wittmann, F.. The wedge splitting test, a new method of performing stable fracture mechanics tests. Engineering Fracture Mechanics 1990;35(1):117-125.

5. Karihaloo, B., Abdalla, H., Xiao, Q.. Coefficients of the crack tip asymptotic field for wedge splitting specimens. Engineering Fracture Mechanics 2003;70(17):2407 - 2420.

6. Steinbrech, R.. R-curve behavior of ceramics. In: Bradt, R., Hasselman, D., Munz, D., Sakai, M., Shevchenko, V., editors. Fracture Mechanics of Ceramics; vol. 9 of Fracture Mechanics of Ceramics. Springer US. ISBN 978-1-4613-6477-1; 1992, p. 187-208. 
7. Mazzei, A., Rodrigues, J., Pandolfelli, V.. Alumina-mullite-zirconia composites obtained by reaction sintering Part II. R-Curve behavior. Journal of Materials Science 2000;35(11):2815-2824.

8. Sun, E., Hsueh, C., Becher, P.. R-curve response of silicon carbide whisker-reinforced alumina: microstructural influence. In: MRS Proceedings; vol. 409. Cambridge Univ Press; 1995, p. 223.

9. McNeill, S., Peters, W., Sutton, M.. Estimation of stress intensity factor by digital image correlation. Engineering Fracture Mechanics 1987;28(1):101-112.

10. Abanto-Bueno, J., Lambros, J.. Investigation of crack growth in functionally graded materials using digital image correlation. Engineering Fracture Mechanics 2002;69:1695-1711.

11. Forquin, P., Rota, L., Charles, Y., Hild, F.. A method to determine the toughness scatter of brittle materials. International Journal of Fracture 2004;125(1):171-187.

12. Mathieu, F., Hild, F., Roux, S.. Identification of a crack propagation law by digital image correlation. International Journal of Fatigue 2012; 36(1):146-154.

13. Williams, M.L.. On the stress distribution at the base of a stationary crack. Journal of Applied Mechanics 1957;24(1):109-114. 
14. Roux, S., Hild, F.. Stress intensity factor measurements from digital image correlation: post-processing and integrated approaches. International Journal of Fracture 2006;140(1-4):141-157.

15. Dehnavi, M.Y., Khaleghian, S., Emami, A., Tehrani, M., Soltani, N.. Utilizing digital image correlation to determine stress intensity factors. Polymer Testing 2014;37:28-35.

16. Hattali, M., Auradou, H., François, M., Lazarus, V.. Numerical and experimental approaches for the determination of two-parameter fracture mechanics in wedge splitting loading. In: 21 $1^{e}$ Congrès Français de Mécanique. Bordeaux (France); 2013, p. 6p.

17. Belrhiti, Y., Pop, O., Germaneau, A., Doumalin, P., Dupré, J., Harmuth, H., et al. Investigation of the impact of micro-cracks on fracture behavior of magnesia products using wedge splitting test and digital image correlation. J Europ Ceramic Soc 2015;35(2):823-829.

18. Belrhiti, Y., Pop, O., Germaneau, A., Doumalin, P., Dupré, J., Huger, M., et al. Refinement of digital image correlation technique to investigate the fracture behaviour of refractory materials. IOP Conference Series: Materials Science and Engineering 2016;119(1):012010.

19. Miyaji, D.Y., Otofuji, C.Z., Cabrelon, M.D., Medeiros, J., Rodrigues, J.A.. The coke effect on the fracture energy of a refractory castable for the petrochemical industry. In: Proceedings of the Unified International 
Technical Conference on Refractories (UNITECR 2013). John Wiley \& Sons, Inc.; 2014, p. 1111-1116.

20. Pereira, A.H.A., Miyaji, D.Y., Cabrelon, M.D., Medeiros, J., Rodrigues, J.A.. A study about the contibution of the $\alpha$ - $\beta$ phase transition of quartz to thermal cycle damage of a refractory used in fluidized catalytic cracking units. Cerâmica 2014;60:449-456.

21. Cabrelon, M.D., Pereira, A.H.A., Medeiros, J., Toledo-Filho, R.D., Rodrigues, J.A.. Efeito do tempo de exposição a uma atmosfera coqueificante na microestrutura e nas propriedades de um concreto refratário usado na indústria petroquímica. Cerâmica 2012;58:195-204.

22. Sutton, M.. Computer vision-based, noncontacting deformation measurements in mechanics: A generational transformation. Applied Mechanics Reviews 2013;65(AMR-13-1009, 050802).

23. Hild, F., Roux, S.. Digital image correlation. In: Rastogi, P., Hack, E., editors. Optical Methods for Solid Mechanics. A Full-Field Approach. Weinheim (Germany): Wiley-VCH; 2012, p. 183-228.

24. Besnard, G., Hild, F., Roux, S.. "Finite-element" displacement fields analysis from digital images: Application to Portevin-Le Chatelier bands. Experimental Mechanics 2006;46:789-803.

25. Leclerc, H., Périé, J., Roux, S., Hild, F.. Integrated digital image 
correlation for the identification of mechanical properties; vol. LNCS 5496. Berlin (Germany): Springer; 2009, p. 161-171.

26. Roux, S., Hild, F., Leclerc, H.. Mechanical assistance to dic. In: Espinosa, H., Hild, F., editors. Full field measurements and identification in Solid Mechanics; vol. Procedia IUTAM, 4. Elsevier; 2012, p. 159-168.

27. Hild, F., Roux, S.. Comparison of Local and Global Approaches to Digital Image Correlation. Experimental Mechanics 2012;52(9):15031519.

28. Fagerholt, E., Børvik, T., Hopperstad, O.S.. Measuring discontinuous displacement fields in cracked specimens using digital image correlation with mesh adaptation and crack-path optimization. Optics Lasers Eng 2013;51(3):299-310.

29. Réthoré, J., Hild, F., Roux, S.. Extended digital image correlation with crack shape optimization. International Journal for Numerical Methods in Engineering 2008;73(2):248-272.

30. Henninger, C., Roux, S., Hild, F.. Enriched kinematic fields of cracked structures. International Journal of Solids and Structures 2010; 47(24):3305-3316.

31. Roux, S., Réthoré, J., Hild, F.. Digital image correlation and fracture: An advanced technique for estimating stress intensity factors of $2 \mathrm{~d}$ and 3d cracks. Journal of Physics D: Applied Physics 2009;42:214004. 
32. Saracura, R.G.M., Canto, R.B., Pandolfelli, V.C., Schmitt, N., Hild, F.. Surface crack network detection on MgO-based refractory castable by digital image correlation. China's Refractories 2015;24(1):32-37.

33. Veselý, V., Sobek, J., Šestáková, L., Frantík, P., Seitl, S.. Multiparameter crack tip stress state description for estimation of fracture process zone extent in silicate composite wst specimens. Fracture and Structural Integrity 2013;(25):Pages-69.

34. Malíková, L., Veselý, V.. The influence of higher order terms of Williams series on a more accurate description of stress fields around the crack tip. Fatigue \& Fracture of Engineering Materials \& Structures 2015;38(1):91-103.

35. Leclerc, H., Neggers, J., Mathieu, F., Hild, F., Roux, S.. Correli 3.0. IDDN.FR.001.520008.000.S.P.2015.000.31500; Agence pour la Protection des Programmes, Paris (France); 2015.

36. Fayolle, X., Calloch, S., Hild, F.. Contrôler une machine d'essai avec une caméra. Mechanics \& Industry 2008;9(5):447-457.

37. Sutton, M., Yan, J., Tiwari, V., Schreier, H., Orteu, J.. The Effect of Out of Plane Motion on 2D and 3D Digital Image Correlation Measurements. Optics and Lasers in Engineering 2008;46(10):746-757.

38. Gupta, M., Alderliesten, R., Benedictus, R.. A review of T-stress and 
its effects in fracture mechanics. Engineering Fracture Mechanics 2015; 134:218-241.

39. Ribeiro, S., Rodrigues, J.A.. The influence of microstructure on the maximum load and fracture energy of refractory castables. Ceramics International 2010;36(1):263-274. 


\section{List of Figures}

1 (a) Picture showing the geometry of WST. The surface has been prepared for DIC purposes. The wedge and cylinders used for the loading are highlighted. $H_{\text {eff }}$ corresponds to the loaded height, $a$ is the crack length considering the loading point as $a=0$, and $\Delta a$ is the measured propagation increment. (b) Loading curves with blue dots showing machine acquisition and red circles interpolated points for each image taken during

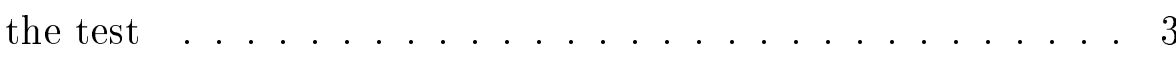

2 Displacement fields for the maximum applied load (i.e., image 96) without considering rigid body translations. (a) Displacements in $x$ direction. (b) Displacements in $y$ direction. Note that the maximum amplitude is less than 0.5 pixel (or $31 \mu \mathrm{m}) \quad 34$

3 Results for three different numbers of terms in Williams' series $\left(p_{f}=[3,8,13]\right)$. The first plot shows the actuator displacement and the second one the loading history. The vertical solid lines are related to the start of each loading and unloading parts. The vertical dashed lines mark the maximum load level for each cycle. The third plot shows the measured crack length with the present methodology. Stress Intensity Factors (SIFs) for mode I in solid lines and mode II in dotted lines are shown in the third graph. The T-stress is finally plotted . . 35 
4 (a) Normalized RMS gray level residual. (b) RMS gray level residual difference between I-DIC and T3-DIC. Both graphs are shown in percentage of the dynamic range of the reference picture and for three different numbers of terms in Williams' series $\left(p_{f}=[3,8,13]\right) \ldots \ldots \ldots \ldots \ldots$

5 Displacement fields for the maximum applied load (i.e., image 96) without considering rigid body motions with $p_{f}=8$. (a) Displacements in $x$ direction. (b) Displacements in $y$ direction. Note that the maximum amplitude is of the order of 0.25 pixel

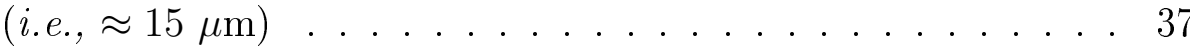

6 Results for three different numbers of terms in Williams' series $\left(p_{f}=[3,8,13]\right)$. Same five plots reported in Figure 3, showing the actuator displacement, the loading history, the measured crack length, the Stress Intensity Factors (SIFs) for mode I in solid lines and mode II in dotted lines and the T-stress, respectively. The vertical solid lines are related to the start of each loading and unloading parts. The vertical dashed lines mark the maximum load level for each cycle . . . . . . . . 38

7 (a) Normalized RMS gray level residual. (b) RMS gray level residual difference between I-DIC and T3-DIC. Both graphs are shown in percentage of the dynamic range of the reference picture and for three different truncations $\left(p_{f}=[3,8,13]\right)$. . 39 
8 Results for the front and back faces with $p_{f}=8$. The measured crack length, SIFs and the T-stress are shown . . . . . 40

$9 \quad$ R-curve for the analyzed test when $p_{f}=8 \ldots \ldots 41$ 


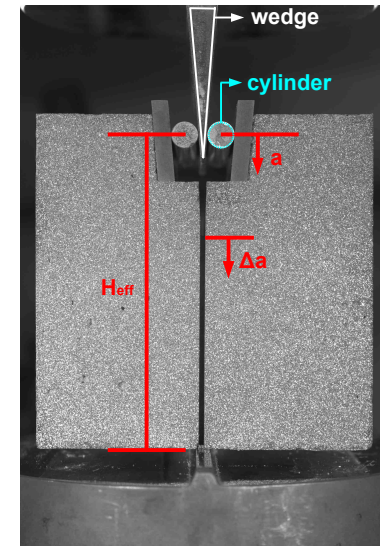

(a)

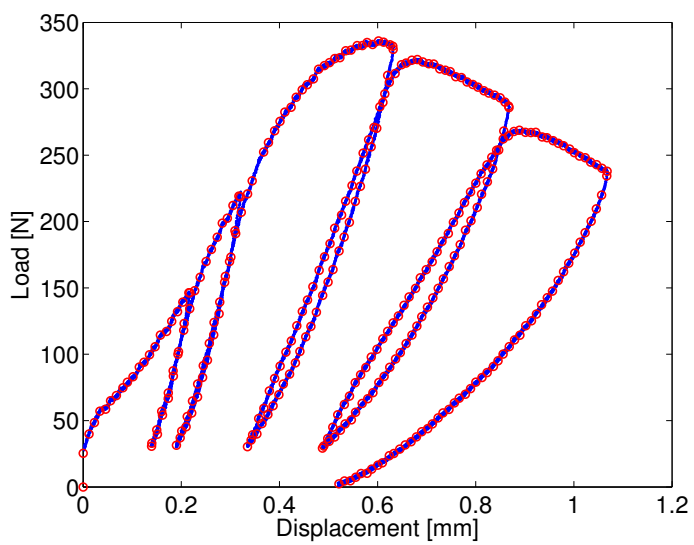

(b)

Figure 1: (a) Picture showing the geometry of WST. The surface has been prepared for DIC purposes. The wedge and cylinders used for the loading are highlighted. $H_{\text {eff }}$ corresponds to the loaded height, $a$ is the crack length considering the loading point as $a=0$, and $\Delta a$ is the measured propagation increment. (b) Loading curves with blue dots showing machine acquisition and red circles interpolated points for each image taken during the test 


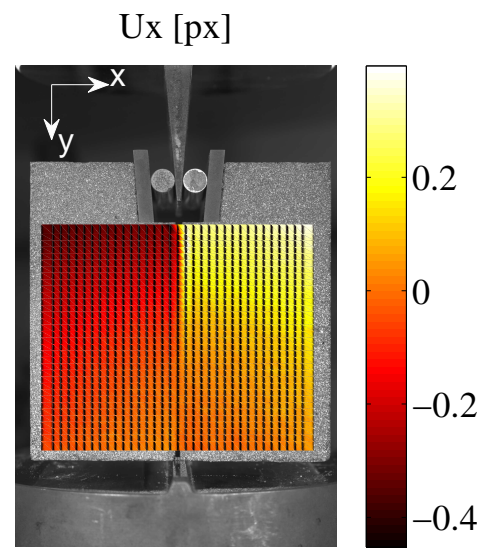

(a)

$\mathrm{Uy}[\mathrm{px}]$

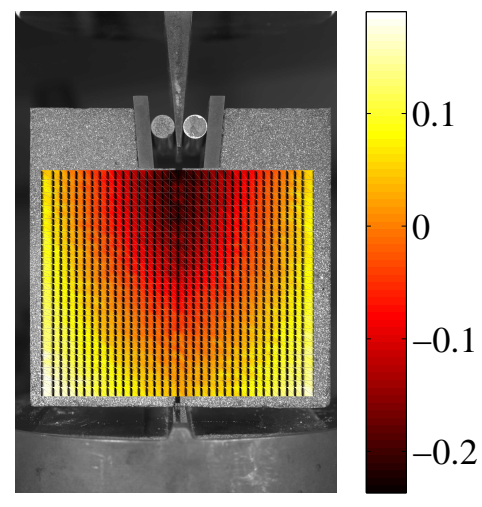

(b)

Figure 2: Displacement fields for the maximum applied load (i.e., image 96) without considering rigid body translations. (a) Displacements in $x$ direction. (b) Displacements in $y$ direction. Note that the maximum amplitude is less than 0.5 pixel (or $31 \mu \mathrm{m}$ ) 

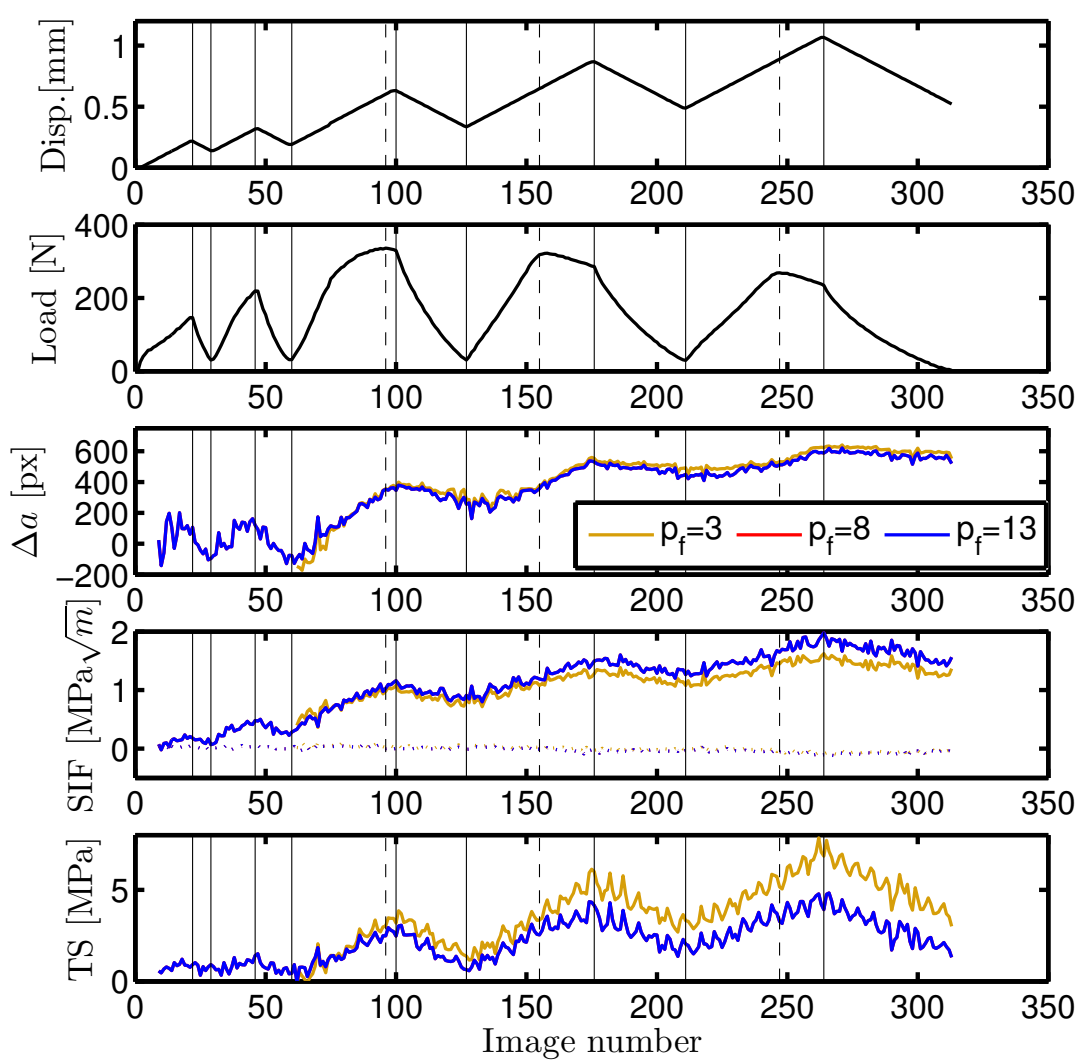

Figure 3: Results for three different numbers of terms in Williams' series $\left(p_{f}=[3,8,13]\right)$. The first plot shows the actuator displacement and the second one the loading history. The vertical solid lines are related to the start of each loading and unloading parts. The vertical dashed lines mark the maximum load level for each cycle. The third plot shows the measured crack length with the present methodology. Stress Intensity Factors (SIFs) for mode I in solid lines and mode II in dotted lines are shown in the third graph. The T-stress is finally plotted 


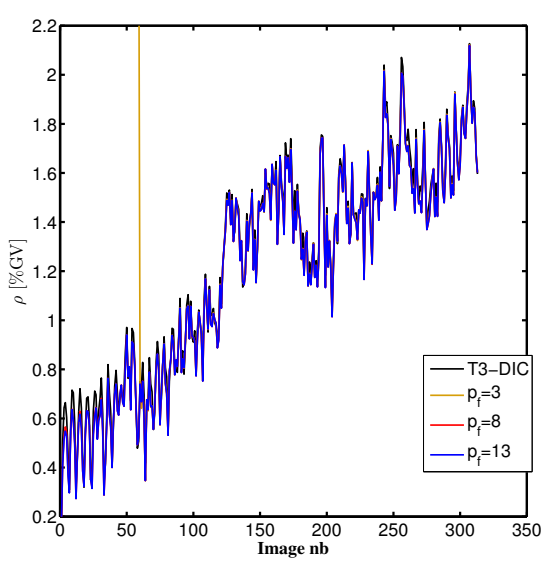

(a)

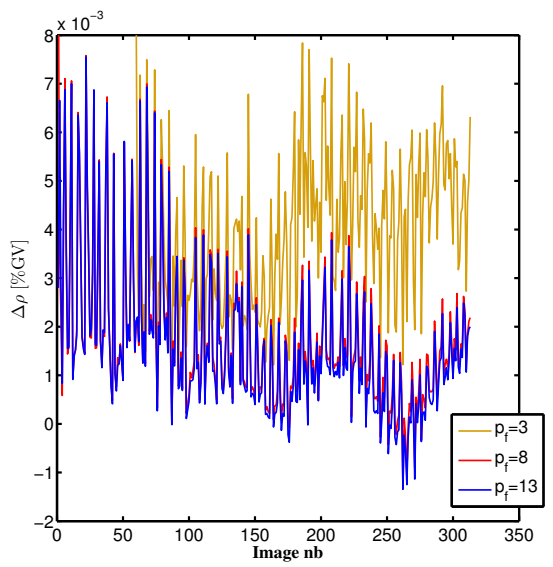

(b)

Figure 4: (a) Normalized RMS gray level residual. (b) RMS gray level residual difference between I-DIC and T3-DIC. Both graphs are shown in percentage of the dynamic range of the reference picture and for three different numbers of terms in Williams' series $\left(p_{f}=\right.$ $[3,8,13])$ 


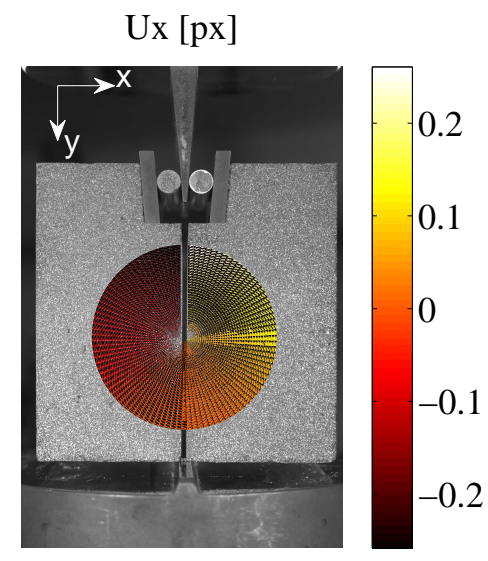

(a)

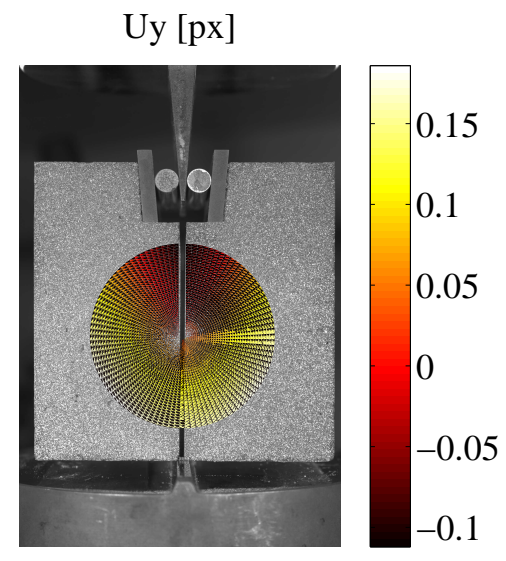

(b)

Figure 5: Displacement fields for the maximum applied load (i.e., image 96) without considering rigid body motions with $p_{f}=8$. (a) Displacements in $x$ direction. (b) Displacements in $y$ direction. Note that the maximum amplitude is of the order of 0.25 pixel (i.e., $\approx 15 \mu \mathrm{m}$ ) 

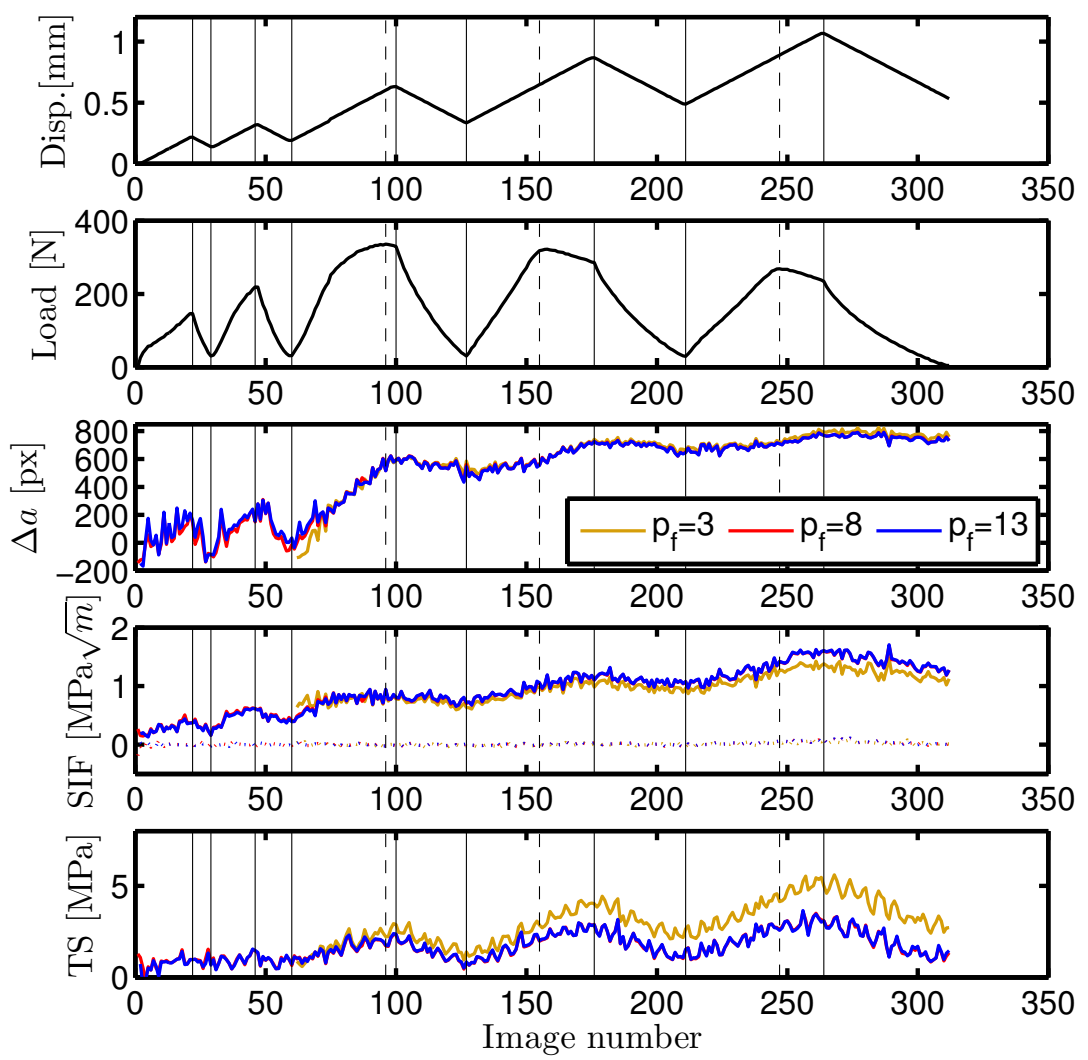

Figure 6: Results for three different numbers of terms in Williams' series $\left(p_{f}=[3,8,13]\right)$. Same five plots reported in Figure 3, showing the actuator displacement, the loading history, the measured crack length, the Stress Intensity Factors (SIFs) for mode I in solid lines and mode II in dotted lines and the T-stress, respectively. The vertical solid lines are related to the start of each loading and unloading parts. The vertical dashed lines mark the maximum load level for each cycle 


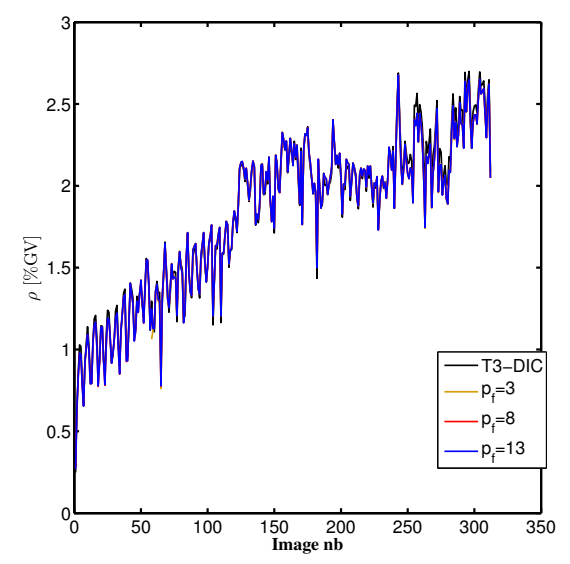

(a)

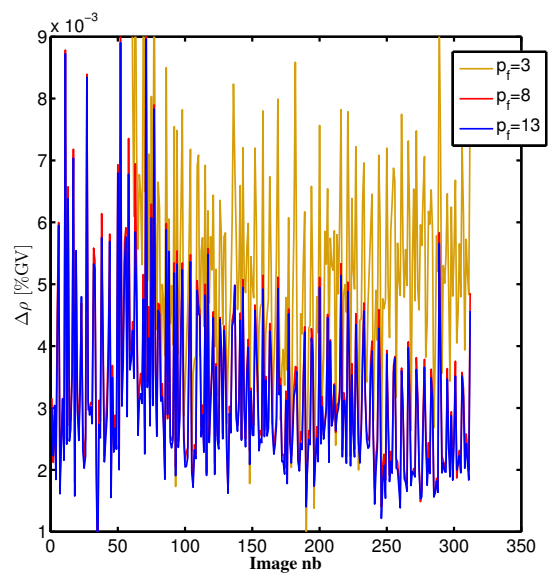

(b)

Figure 7: (a) Normalized RMS gray level residual. (b) RMS gray level residual difference between I-DIC and T3-DIC. Both graphs are shown in percentage of the dynamic range of the reference picture and for three different truncations $\left(p_{f}=[3,8,13]\right)$ 

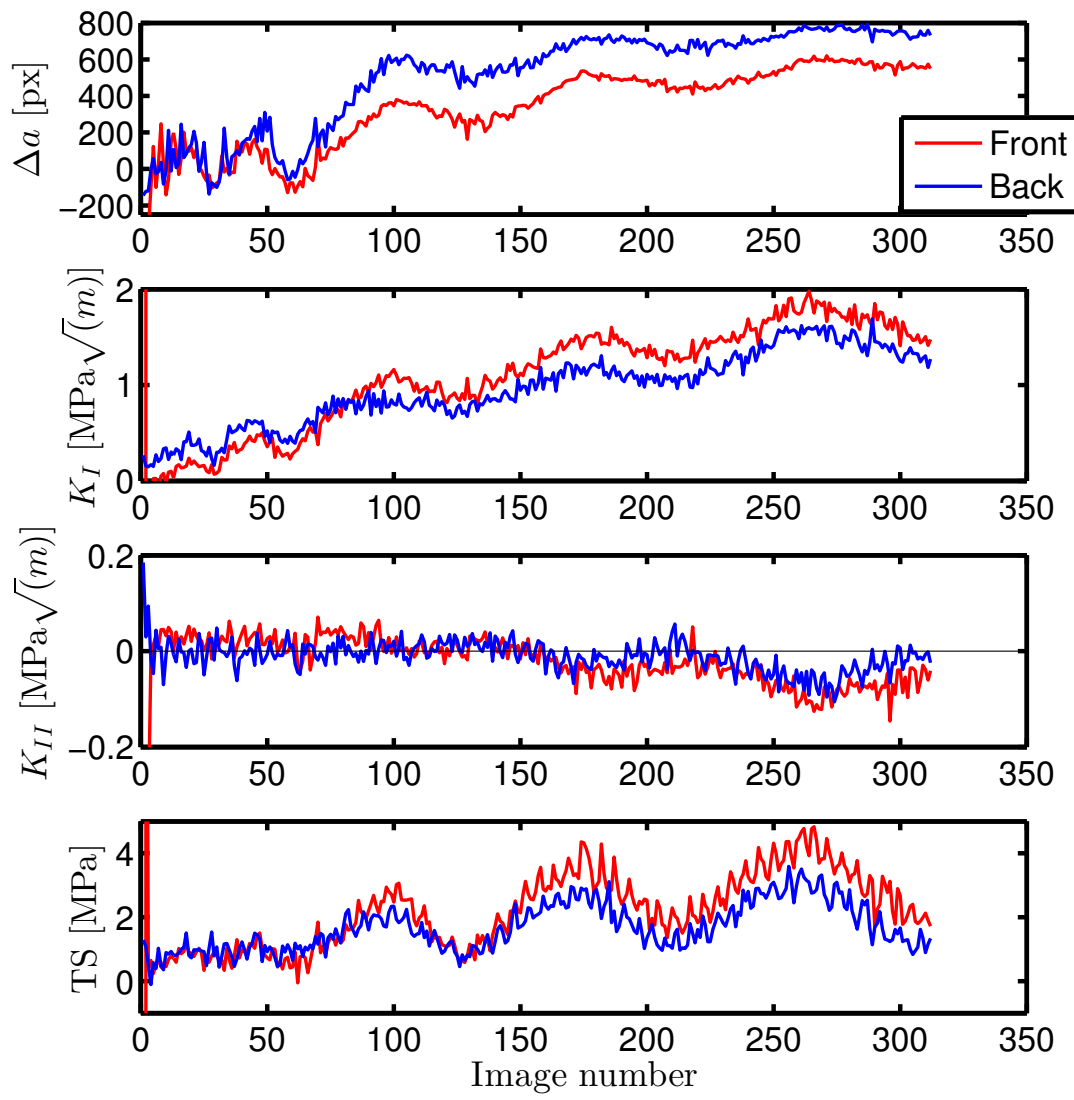

Figure 8: Results for the front and back faces with $p_{f}=8$. The measured crack length, SIFs and the T-stress are shown 


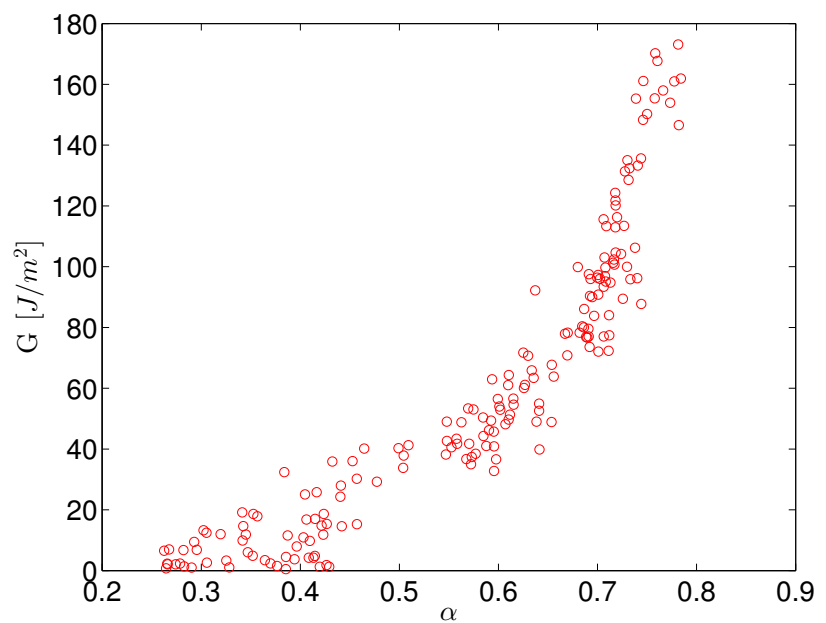

Figure 9: R-curve for the analyzed test when $p_{f}=8$ 